\title{
REVISÃO BIBLIOGRÁFICA SOBRE A PROFILAXIA DA CONJUNTIVITE GONOCÓCICA NO RECÉM-NASCIDO
}

\author{
Maria Alice Tsunechiro*
}

TSUNECHIRO, M. A. Revisão bibliográfica sobre a profilaxia da conjuntivite gonocócica no recém-nascido. Rev. Esc. Enf. USP, São Paulo, 13(3):275-286, 1979.

Em 1881, Credé introduziu a instilação ocular de solução de nitrato de prata em recémnascidos, logo após o parto, a fim de prevenir a conjuntivite gonocócica. Não bostante a utilização quase secular do Método de Credé, existe controvérsia entre os autores consultados, quanto à sua indicação, ao modo de aplicação e à substituição do agente anti-bacteriano. Os estudos sobre a conjuntivite neonatal gonocócica e a gonorréia em gestantes set referem: a determinados hospitais e não se encontraram estudos nacionais. O problema da falha e riscos do Método de Credé é atribuido à aplicação incorreta da técnica. A autora sugere a continuação do uso rotineiro do Método de Credé em todos os recém-nascidos, segundo normas especiais estabelecidas.

Há muitos anos, a prevenção e o controle de infeç̧ões, em recém-nascidos, vêm sendo um desafio constante para os profissionais de muitas maternidades, apesar do grande avanço da bacteriologia e da descoberta de antibióticos que permitem melhores condições para o diagnóstico, o tratamento e, principalmente, a profilaxia das mesmas.

Os recém-nascidos são vulneráveis a vários tipos de infecções e, entre estas, uma das mais comuns é a conjuntivite.

Segundo CLARK \& CULLER ${ }^{20}$ e MARGILETH ${ }^{44}$, a conjuntivite do recém-nascido e a oftalmia neonatal são sinônimos relacionados a qualquer inflamação ou infeç̧ão conjuntival que ocorra nas duas primeiras semanas de vida da criança.

FRIENDLY 27 e WILENSKY ${ }^{90}$ classificam a conjuntivite neonatal em três grupos etiológicos: $10^{\circ}$ ) irritativa, geralmente causada por reação à solução de nitrato de prata usada na profilaxia anti-gonocócica; $2^{\circ}$ ) infecciosa bacteriana, causada por estafilococos, estreptococos, pneumococos, hemófilos, coliformes e gonoco$\cos ; 3^{\circ}$ ) infecciosa não bacteriana, causada por virus de inclusão blenorrágica.

Historicamente, para MELLIN \& KENT ${ }^{49}$, o gonococo é o maior agressor na conjuntivite neonatal. Por sua vez, BARSAM ${ }^{7}$ e WILENSKY ${ }^{90}$, afirmam que a mais perigosa conjuntivite neonatal é a de origem gonocócica.

A conjuntivite neonatal gonocócica é definida como um processo infeccioso da conjuntiva ocular causada por Neisseria gonorrhoeae, que aparec, , quase sempre, a partir do $3 .^{\circ}$ ou $4 .^{\circ}$ dia de vida, manifestando-se como uma hiperemia conjuntival, edema das pálpebras e secreção catarral amarelada e profusa, em ambos os olhos - Professor Assistente das disciplinas Enfermagem Obstétrica e Neonatal e Enfermagem Ginecológica
da EEUSP. 
do recém-nascido. Se não for tratada oportunamente, essa infecção poderá levar à cegueira, devido à ação corrosiva do gonococo na córnea, causadora de ulcerações e perfuração da mesma.

A contaminação bacteriana dos olhos do recém-nascido pode ocorrer antes, durante ou após o parto. Na maioria dos casos de conjuntivite neonatal gonocócica, a contaminação ocular do recém-nascido ocorre durante o nascimento, na passagem pelo canal do parto infectado por gonococo $11,23,35,85,86,87$. Este meio de contaminação gonocócica é o mais comum, pois, de acordo com BOTELLA LLUSIÁ ${ }^{13}$, a localização mais freqüente do gonococo na mulher adulta é no colo uterino. Por outro lado, CAVE et alii ${ }^{17}$ e SCHAMALE et alii ${ }^{72}$ verificaram, por meio de cultura do material colhido dos órgãos genitais, da uretra e do reto de gestantes, que o colo uterino e a vagina foram os locais de maior incidência de Neisseria gonorrhoeae. Com menos freqüência, a contaminação por gonococo pode ocorrer também na cavidade amniótica, antes do nascimento, principalmente quando há rotura das membranas ovulares $4,31,35,51,52,86,87$. PEARSON ${ }^{62}$ e THOMPSON et alii ${ }^{86}$ mencionam casos de recém-nascidos que, ao nascer, apresentaram secreção ocular purulenta, confirmada posteriormente, por meio de cultura, como de origem gonocócica. NICKERSON ${ }^{52}$ e THOMPSON et alii ${ }^{86}$ relatam casos de recém-nascidos de cesárea que tiveram conjuntivite gonocócica nos primeiros dias de vida. HANDSFIELD et alii ${ }^{31}$ encontraram Neisseria gonorrhoeae, em aspirações orogástricas de recém-nascidos, feitas logo após o nascimento. A conjuntiva do recém-nascido pode ser contaminada após o nascimento, por contato com pessoas (pessoal da equipe hospitalar, pais, familiares e outras) e com fômites portadores de gonococo $8,67,85,86$.

De acordo com BARRETT-CONNOR ${ }^{5}$, a conjuntivite gonocócica pode ocorrer em qualquer idade mas é considerada uma doença própria do recém-nascido, ocorrendo principalmente em crianças menores de cinco dias de idade, nascidas de mães com gonorréia.

Há já muito tempo a conjuntivite neonatal gonocócica tem sido um problema sanitário sério, como se pode constatar no trabalho de SMITH \& HALSE ${ }^{81}$. Estes autores fazem um relato histórico dos esforços empreendidos para o controle da infeç̧ão gonocócica nos olhos do recém-nascido, comentando que, em 1881, Credé descobriu um método para prevenir essa infecção.

CREDÉ 21 relata que, em 1880, em Leipzig, utilizou a instilação de uma gota de nitrato de prata a $2 \%$ em cada olho dos recém-nascidos, logo após o nascimento, como um método profilático da conjuntivite gonocócica. Relata ainda que, após a introdução dessa medida, a incidência da conjuntivite gonocócica e, conseqüentemente, da cegueira, decresceu rapidamente. THYGESON ${ }^{87}$ considera esta descoberta uma das grandes vitórias da medicina científica. FORBES \& FORBES ${ }^{25}$ apresentam Credé como um pioneiro no campo da medicina preventiva, cujas normas são válidas hoje, como o foram em 1881 .

$O$ efeito benéfico do uso do nitrato de prata na prevenção da conjuntivite gonocócica e, por conseguinte, da cegueira, mesmo antes da descoberta dos antibióticos, é apresentado na publicação da National Society for the Prevention of Blindness ${ }^{65}$, onde se verifica que a freqüência de novas admissões em escolas para cegos, devido à conjuntivite neonatal gonocócica, decresceu gradativamente de $28,2 \% \mathrm{em}$ 1906-1907 para 7,4\% em 1937-1938. 
BARSAM ${ }^{7}$ comenta que a adoção da legislação que obriga o uso do nitrato de prata a $1 \%$ nos olhos dos recém-nascidos, como agente profilático, logo após o nascimento, em muitas partes do mundo, tem trazido um grande avanço na prevenção da conjuntivite gonocócica. Esse autor, continuando o estudo apresentado na publicação da National Society for the Prevention of Blindness, verificou que a freqüência de novas admissóes em escolas para cegos, devido à conjuntivite neonatal gonocócica, continuou decrescendo, chegando em 1958-1959 a 0,3\%.

Em vista disso, a profilaxia da conjuntivite neonatal gonocócica, pela instilação de nitrato de prata a $1 \%$ nos olhos do recém-nascido, é conhecida mundialmente como o Método de Credé e, atualmente, ainda é aceito e utilizado na maioria das maternidades.

Na literatura consultada sobre este assunto, pode-se verificar que, para vários autores, o Método de Credé é eficaz e necessário, como a principal medida profilática contra a conjuntivite gonocócica do recém-nascido. Porém, verifica-se também que a eficácia do nitrato de prata como agente profilático e a morbidade que ele produz têm sido questionadas, de tempos em tempos, por muitos autores.

A seguir são citados autores que relatam casos de recém-nascidos que adquiriram a conjuntivite gonocócica nos primeiros dias de vida, apesar de terem recebido a instilação ocular da solução de nitrato de prata a $1 \%$ logo após o nascimento. Esses casos ocorreram em determinados hospitais, não representando, portanto, dados nacionais ou mesmo locais. Assim, em hospitais dos Estados Unidos da América, autores como ALLUE et alii ${ }^{2}$ observaram 7 casos de conjuntivite neonatal gonocócica num periodo de 18 meses; ARMSTRONG et alii ${ }^{4}, 43 \mathrm{em} 7$ anos; BROWN et alii ${ }^{15}, 17$ em 6 anos; FRIENDLY ${ }^{27}, 5$ em 12 meses; PEARSON ${ }^{62}, 38$ em 10 anos; PIEROG et alii ${ }^{63}, 11 \mathrm{em} 3$ anos e meio; THATCHER \& PETTIT ${ }^{85}, 2 \mathrm{em}$ 6 meses; e THOMPSON et alii ${ }^{86}, 6$ em 1 ano. Em um hospital da Finlândia, öSTERLUND e alii ${ }^{59}$ observaram 4 casos de conjuntivite neonatal gonocócica num período de 2 anos.

ARMSTRONG et alii ${ }^{4}$ são de opinião que, mesmo sendo feita a profilaxia com a solução de nitrato de prata a $1 \%$, há um risco de $2 \%$ dos recém-nascidos de mães infectadas adquirirem a conjuntivite neonatal gonocócica.

Muitos autores têm descrito trabalhos onde foram utilizados outros agentes anti-bacterianos para a profilaxia da conjuntivite neonatal gonocócica, a fim de substituir o nitrato de prata. $\mathrm{Na}$ mioria dos distritos dos Estados Unidos da América, de acordo com a declaração da NATIONAL SOCIETY FOR THE PREVENTION OF BLINDNESS - COMMITTEE ON OPHTHALMIA NEONATORUM ${ }^{51}$, é obrigatório o uso de nitrato de prata ou de outro agente de eficácia equivalente, para a profilaxia da conjuntivite neonatal gonocócica. Assim sendo, foram desenvolvidos nesse país estudos com diferentes agentes para a profilaxia desta conjuntivite e vários antibióticos foram usados na tentativa de substituir o nitrato de prata, como a penicilina ${ }^{1,9,22,26,29,32,44,89}$, a aureomicina ${ }^{20}$, a tetraciclina ${ }^{15,48}$, a bacitracina ${ }^{29,44,64}$ e a eritromicina ${ }^{19}$; foram utilizadas também as sulfus ${ }^{10}$. Com a mesma finalidade, em outros países, foram utilizadas a penicilina ${ }^{42}$, a sulfa ${ }^{52}$, a tetraciclina ${ }^{55}$ e um composto quaternário de amônio ${ }^{47}$.

Na maioria dos trabalhos acima citados, as drogas foram usadas paralelamente ao nitrato de prata e algumas mostraram ser igualmente eficazes, mas não su- 
riores, exceto na baixa freqüência de conjuntivite química. A penicilina foi a mais recomendada, mas o argumento principal contra seu uso é a possibilidade de sensibilização. Entretanto, LERMAN ${ }^{40}$ comenta que a sensibilização à penicilina em criança, com penicilina de uso tópico, nunca foi claramente relatada; apesar disto, a possibilidade desta ocorrência tem eliminado a droga como agente de escolha, na rotina da profilaxia da conjuntivite neonatal gonocócica.

Após uma pesquisa em hospitais americanos, NISHIDA \& RISEMBERG 53 constataram que pouco mais de $20 \%$ destes hospitais não usam o Método de Credé devido à conjuntivite química. Estes autores verificaram, também, que $90 \%$ dos recém-nascidos que receberam a instilação ocular da solução de nitrato de prata a $1 \%$ têm conjuntivite química nas primeiras 24 horas de vida, sendo raro após este período.

Para alguns autores ${ }^{1,12,42,58}$ a ocorrência da conjuntivite química é uma desvantagem do Método de Credé. Por outro lado, SNOWE \& WILFERT ${ }^{83}$ informam que pessoas inexperientes podem supor que toda a conjuntivite que surge nos primeiros dias de vida é consequiência da profilaxia ocular com o nitrato de prata, retardando, às vezes, o diagnóstico de conjuntivite gonocócica.

Igualmente, a ocorrência de danos oculares causados por substituições acidentais do nitrato de prata, ou por soluçôes mais concentradas do mesmo, têm levado alguns autores a contraindicar o Método de Credé nos recém-nascidos. DIECKMAN ${ }^{24}$ refere que 15 recém-nascidos receberam instilação ocular da solução de nitrato de prata a $10 \%$ por erro do pessoal da farmácia; comenta que, possivelmente, devido ao uso rotineiro de irrigação com solução salina, logo após a instilação, não ocorreu dano cular permanente. GIFFIN JUNIOR ${ }^{30}$ descreve 2 casos de dano ocular permanente em recém-nascidos por aplicação acidental, nos olhos, de nitrato de prata amoniacal $(25$ a $30 \%$ ) de uso dentário; o autor esclarece que este erro foi do pessoal da farmácia.

A solução de nitrato de prata a $1 \%$, quando acondicionada em ampolas de cera individuais, previne a evaporação da água da mesma evitando torná-la mais concentrada ${ }^{66}$. No Brasil, segundo BELFORT JUNIOR et alii ${ }^{8}$, não temos essa solução acondicionada em ampolas de cera.

Vários trabalhos têm sido apresentados com a finalidade de mostrar que, $\mathrm{cm}$ locais onde a profilaxia foi abandonada ou não é usada, houve ocorrência de conjuntivite neonatal gonocócica.

SEEDORF 77 realizou uma investigação em duas maternidades de Copenhagen; em uma delas (maternidade A) os recém-nascidos não receberam tratamento ocular e em outra (maternidade B) os recém-nascidos receberam o tratamento ocular pelo Método de Credé. Este autor não menciona o tamanho de sua população e cita apenas o número de recém-nascidos que apresentaram conjuntivite de etiologia variada. Em vista disso, conclui que, do total de 92 recém-nascidos da maternidade $\mathrm{A}$ que apresentaram conjuntivite, $7(7,6 \%)$ foram de origem gonocócica e na maternidade $B$, do total de 11 recém-nascidos com conjuntivite, nenhum deles foi causada por gonococo.

SMITH ${ }^{82}$ fez um estudo retrospectivo dos casos de conjuntivite neonatal em Glasgow, de 1963 a 1968 , e verificou que a Neisseria gonorrhoeae foi a causa mais 
comum da infecção ocular. De um total de 91 casos de conjuntivite neonatal, 55 recém-nascidos tiveram a conjuntivite gonocócica. Este autor esclarece que, em Glasgow, não é utilizado método algum de profilaxia ocular gonocócica e sugere que seja introduzida a profilaxia contra essa infeç̧ão em recém-nascidos com maior risco de adquirir a doença, ou seja, recém-nascidos ilegítimos e de classe social mais baixa, onde a incidência da conjuntivite gonocócica é mais alta.

SCHOFIELD \& SHANKS ${ }^{74}$ informam que foram notificados 48 casos de conjuntivite gonocócica, no departamento de venerologia em Glasgow, no período de 1964 a 1968.

ONYANGO-OGONY \& HETLAND-ERIKSEN ${ }^{56}$ atenderam, num periodo de 3 meses, 34 recém-nascidos com conjuntivite neonatal, no Mulago Hospital, no Kenia; destes, $25(73 \%)$ tiveram a conjuntivite de origem gonocócica. Estes autores informam que, neste período, a instilação ocular de nitrato de prata estava suspensa e recomendam a reintrodução dessa medida profilática na área do $\mathrm{Mu}$ lago Hospital.

OTITI ${ }^{60}$ comenta que a conjuntivite neonatal é comum em Uganda, mas não mostra dados; apresenta um estudo realizado de maio de 1969 a novembro de 1971, onde 246 recém-nascidos com conjuntivite neonatal foram atendidos no departamento de oftalmologia do Mbale Hospital. Destes recém-nascidos, 54 (22\%) apresentaram Neisseria gonorrhoeae na secreção ocular, com a média do período de incubação de 2 dias, sendo a segunda causa mais comum; o Staphylococcus aureus aparece em primeiro lugar.

Em vista da ausência de casos de conjuntivite neonatal gonocócica em seus trabalhos, alguns autores não acham necessário qualquer tipo de tratamento profilática da conjuntivite neonatal.

LEFF ${ }^{37}$ não encontrou caso de conjuntivite neonatal gonocócica em 4.500 recém-nascidos que receberam apenas a irrigação ocular com solução salina normal ou água esterilizada. Este autor afirma que devem ser abolidas as leis que obrigam o uso de nitrato de prata ou de outras substancias e que no caso eventual de conjuntivite gonocócica, esta poderia ser tratada facilmente com penicilina.

MARGILETH ${ }^{44}$, após estudo comparativo entre o uso de penicilina e de bacitracina, concluiu que a melhor profilaxia é a observação cuidadosa dos olhos do recém-nascido, após o nascimento, sem que eles sejam tocados ou que neles seja usada qualquer droga.

SOLOMONS et alii ${ }^{84,}$ de junho de 1956 a abril de 1958, estudaram 2.212 recém-nascidos que receberam a instilação de 2 gotas de água destilada, logo após $\checkmark$ nascimento, e 3.268 recém-nascidos que não receberam tratamento, num total de 5.480 recém-nascidos. Estes autores não observaram conjuntivite gonocócica nestes recém-nascidos e concluiram que a instilação profilática de nitrato de prata ou de antibiótico nos olhos de todos os recém-nascidos deve ser reconsiderada, principalmente devido à rápida resposta da infeç̧ão gonocócica ao tratamento com antibiótico.

Da mesma forma, BOONE et alii ${ }^{12}$ são de opinião que o tratamento deveria ser instituído apenas quando houvesse o aparecimento da doença e comentam que há controvérsia entre os autores, quanto à realização da profilaxia anti-gonocócica em todos os recém-nascidos. 
LEHRFELD ${ }^{38}$ e SHAW 78 acham que a profilaxia rotineira deveria ser reavaliada; novamente SHAW ${ }^{80}$ enfatiza que, por mais sucesso que o Método de Credé tenha, não há razão para perpetuá-lo, devido aos problemas e dificuldades que podem ocorrer na sua aplicação.

Entretanto, GREENBERG \& VANDOW 29 afirmam que nenhuma conclusão válida pode ser tomada em relação à eficácia dos agentes profiláticos, se o risco de infecção entre os recém-nascidos não for determinado.

MELLIN ${ }^{50}$ considera mais importante a avaliação da necessidade ou não da profilaxia ocular anti-gonocócica do que a escolha do agente anti-bacteriano.

É oportuno salientar que a ausência de casos de conjuntivite neonatal gonocócica pode ser devido tanto à eficácia da droga usada como agente profilático quanto ao fato das mães não terem gonorréia no momento do parto. LEFF 37 e SOLOMONS et aliii ${ }^{84}$ não pesquisaram a existência ou a ausência de gonorréia nas mães destes recém-nascidos.

BARRETT-CONNOR ${ }^{6}$ e HOLMES ${ }^{33}$ afirmam que a gonorréia, atualmente, é a causa de somente uma pequena proporção de casos de conjuntivite neonatal e que os mais comuns são devido a outras bactérias. Para alguns autores 33,69 , o Método de Credé não tem ação profilática sobre outras conjuntivites, a não ser a de origem gonocócica.

Segundo ALLUE \& RUBIO², a verdadeira incidência de gonorréia na população em geral é desconhecida. Uma das razões é o caráter assintomático da infecção gonocócica em mulheres. BROWN ${ }^{14}$ afirma que a incidência de gonorréia assintomática em mulheres é em torno de 60 a $90 \%$. SCHROETER \& LUCAS ${ }^{75}$ mencionam que $80 \%$ das mulheres com gonorréia são assintomáticas e permanecem na população, como um reservatório. CAMPOS SALAS ${ }^{16}$ comenta que o breve período de incubação do gonococo (em geral 3 dias) permite o contágio de maior número de doentes que propagam o mal e aí sucessivamente, de tal maneira que se pode dizer que a propagação se realiza em progressão geométrica. Associando esse fato ao caráter assintomático da gonorréia na maioria das mulheres, torna-se difícil o controle epidemiológico desta doença intimamente ligada ao comportamento sexual dos indivíduos ${ }^{61}$.

Em alguns trabalhos pode-se verificar que a freqüência de infecção gonocócica aumentou em mulheres jovens ( 15 a 29 anos). Por conseguinte, a incidência de gestantes com gonorréia provavelmente aumentou em proporções similares; e assim, também, o risco de infecção ocular gonocócica em recém-nascidos 16,36,57,61,91.

Em vista disto, a profilaxia da conjuntivite gonocócica em recém-nascidos, por meio de triagem e tratamento das mães infectadas, no pré-natal, é recomendada por vários autores, baseados no princípio fundamental de que toda medida preventiva na saúde é o controle da doença na sua fonte. Assim, o tratamento da mãe infectada por gonococo é considerado o melhor método profilático para o recémnascido $3,28,35,38,39,59,63,68,70,71,73,78,79,80,83,85,86$. Por outro lado, SARREL \& PRUETT 70 comentam que o pré-natal é também uma fase excelente para educar, individualmente, a gestante infectada sobre as doenças sexualmente transmissiveis.

No entanto, não se pode afirmar que todas as mulheres com gonorréia são identificadas pelos meios disponíveis. Atualmente, para a cultura na pesquisa de Neis- 
seria gonorrhoeae, é utilizado o meio de Thayer-Martin (agar-chocolate, adicionado de vancomicina, colistina e nistatina). Segundo SCHROETER \& PAZIN ${ }^{76}$, aproximadamente $90 \%$ das mulheres com gonorréia podem ser diagnosticadas, se for colhido material de vários locais, ou seja, colo uterino, vagina, uretra e reto; e em $80 \%$, em material colhido só do colo uterino. NOLAN \& OSBORNE ${ }^{54}$ referem que se pode obter cultura positiva do colo uterino infectado em $90 \%$ dos casos. HOLMES ${ }^{33}$ menciona freqüência de cultura positiva do colo uterino em $80 \%$ e da uretra em 50 a $60 \%$, em mulheres com gonorréia.

Do que foi mencionado, pode-se constatar a importância do conhecimento da incidência de gonorréia, em gestantes, para a adoção do Método de Credé nos recém-nascidos. MANN ${ }^{43}$ e GREENBERG \& VANDOW ${ }^{29}$ sugerem o abandono da profilaxia em locais e hospitais onde a incidência de gonorréia é rara.

$\mathrm{Na}$ revisão bibliográfica, não foram encontrados trabalhos que mencionem dados nacionais ou regionais de nenhum país; somente encontram-se dados de determinados hospitais, sobre a incidência de gonorréia em gestantes. Estes trabalhos são citados a seguir: ALLEN \& BARRERE ${ }^{1}-1,5 \%$, CAVE et alii ${ }^{17}-5,5 \%$, CHARLES et alii ${ }^{18}-7,3 \%$, DAVIDSON et alii $22-2,7 \%$, KRAUS \& YEN ${ }^{36}$ $-5,73 \%$, ÖSTERLUND et alii $59-0,43 \%$, SARREL \& PRUETT $70-6 \%$ e WATERS \& ROULSTON ${ }^{88}-2,63 \%$.

Geralmente, o problema das falhas e riscos do Método de Credé. é atribuído à aplicação incorreta da técnica. ISRAEL et alii ${ }^{35}$ são de opinião que a profilaxia deveria ser administrada por pessoal experiente e que muitas falhas poderiam ser atribuídas à inadequada administração da droga. Convém ressalatr que CREDÉ 21 havia restringido a aplicação da profilaxia ocular, exclusivamente, a médicos e obstetrizes. Por esse motivo, MATHESIUS ${ }^{47}$ afirma que a questão não é mudar ou abandonar totalmente o método, mas aplicá-lo rigorosamente, de acordo com as normas estabelecidas.

ÖSTERLUND et alii 59 acreditam que o caráter rotineiro da profilaxia, assim como a baixa freqüência da infeç̧ão gonocócica $(0,45 \%)$, talvez possa levar a um certo descuido na instilação, que nem sempre é fácil.

BLAKE et alii ${ }^{11}$ e MARLOW ${ }^{46}$ fazem referência também à dificuldade na instilação ocular da solução de nitrato de prata e à importância de a enfermeira estar certa de que a gota caiu no saco conjuntival.

Na prática diária, observa-se que um dos problemas mais comuns na aplicação do Método de Credé é a dificuldade para abrir os olhos do recém-nascido e expor o saco conjuntival; esta dificuldade é notada, principalmente, na aplicação no segundo olho, possivelmente devido à ação irritante do nitrato de prata instilado no primeiro olho. SHAW ${ }^{79}$ também afirma que é difícil abrir os olhos do recémnascido e introduzir a gota da solução de nitrato de prata, especialmente no segundo olho. SHAW ${ }^{80}$ comenta que a introdução da gota de nitrato de prata é traumática, dev،do à dificuldade em abrir adequadamente as pálpebras.

1:RETT-CONNOR ${ }^{5}$ considera não muitas claras as razões das falhas da profilaxia da conjuntivite gonocócica com nitrato de prata; porém, acredita que, em alg casos, a droga pode não ter sido instilada corr tamente ou pode não ter sido colocada no segundo olho devido ao severo blefaroespasmo que está associado com 
a aplicação no primeiro olho. Cita, também, que a lavagem dos olhos do recém-nascido com solução salina isotônica, após a instilação pode precipitar o ion prata, inativando a medicação no olho.

WILENSKY ${ }^{00}$ não recomenda a irrigação ocular com solução salina, quando é empregada a solução de nitrato de prata, porque o ion cloreto precipita a prata e destrói a sua atividade germicida. LeROUX \& YEE ${ }^{41}$ recomendam lavar os olhos com solução salina, imediatamente após a instilação da solução de nitrato de prata, para prevenir a conjuntivite química. MARLOW ${ }^{45}$, INGALLS \& SALERNO ${ }^{34}$ e REEDER et alii ${ }^{67}$ recomendam tanto a irrigação ocular com solução salina como com água destilada para diminuir a incidência de conjuntivite química; INGALLS \& SALERNO ${ }^{34}$, porém, comentam que em alguns berçários é empregada a solução salina isotônica para inativar o nitrato de prata que é irritante para a mucosa conjuntival, pela formação de um precipitado, o cloreto de prata, e que outros consideram esse precipitado irritante e preferem o uso de água.

A National Society for the Prevention of Blindness - Committee on Ophthalmia Neonatorum ${ }^{51}$ e a Secretaria de Estado da Saúde do Governo do Estado de São Paulo ${ }^{69}$ não recomendam a irrigação dos olhos após a instilação da solução de nitrato de prata a $1 \%$.

NISHIDA \& RISEMBERG ${ }^{53}$ estudaram, de janeiro de 1973 a fevereiro de 1974, 1.000 recém-nascidos de um hospital de Baltimore e concluíram que não há diferença na incidência da conjuntivite química, quer seja feita a irrigação com água destilada, quer com solução salina, ou mesmo sem qualquer irrigação após a instilação da solução oftálmica do nitrato de prata. Por este fato, estes autores não aconselham a irrigação ocular após a instilação do nitrato de prata.

Nesta revisão bibliográfica, encontrou-se apenas um trabalho realizado em nosso meio. BELFORT JUNIOR et alii ${ }^{8}$ fizeram um levantamento em 30 maternidades na cidade de São Paulo, sobre a profilaxia da conjuntivite gonocócica do recém-nascido. Estes autores constataram que 10,5\% das maternidades da amostra executavam adequadamente a profilaxia da conjuntivite neonatal gonocócica, usando o Método de Credé de acordo com as normas internacionais; $26,3 \%$ das maternidades usavam o nitrato de prata em concentração incorreta $(0,0$ a $1,5 \%)$; $57,8 \%$ as maternidades utilizavam colírio (Argirol) de eficácia criticável e muito inferior ao nitrato de prata; e 5,2\% das matenidades empregavam antibiótico associado a corticóide. Os autores ressaltam ainda que, em geral, o preparo do pessoal encarregado da antissepsia ocular é insuficiente, desconhecendo eles, muitas vezes, a técnica correta da aplicação do Método de Credé e a sua finalidade.

Vários aspectos abordados neste estudo são significativos e permitem que se façam algumas sugestões:

1. Continuação do uso rotineiro da instilação ocular da solução de nitrato de prata a $1 \%$ em todos os recém-nascidos, logo após o nascimento, segundo normas especiais estabelecidas.

Desde 1977, por decreto, em todo o Estado de São Paulo, é obrigatória a instilação de uma gota de solução de nitrato de prata a $1 \%$, nos olhos de todos os recém-nascidos, dentro de uma hora após o nascimento ${ }^{69}$. 
Apesar a existência de controvérsia entre alguns autores consultados, sobre o Método de Credé, até que se façam estudos controlados não se justifica abandonar ou omitir este método e expor os recém-nascidos à infeç̧ão ocular gonocócica de origem materna ou de outras fontes de contaminação.

Consideraram-se como argumentos importantes para a continuação do Método de Credé o desconhecimento, em nosso meio, da incidência de gonorréia na população geral $e$ as declarações de vários autores sobre o crescente aumento da incidência dessa moléstia em adultos jovens. Por outro lado, na prática, seria inviável a implantação de exame bacteriológico do material cervical de gestantes, para cultura de Neisseria gonorrhoeae, devido ao alto custo de pessoal e material. Além disso, o Método de Credé é aceito por vários autores consultados, apesar do nitrato de prata causar a conjuntivite química na maioria dos recém-nascidos que receberam essa profilaxia.

2. Observação dos recém-nascidos após a instilação ocular da solução de nitrato de prata a $1 \%$ pelo pessoal médico e de enfermagem, durante a sua permanência no hospital.

Na falta de segurança total do Método de Credé, como foi mencionado anteriormente, há necessidade de se alertar o pessoal que cuida do recém-nascido sobre a probabilidade de ocorrer a conjuntivite gonocócica, mesmo que o recém-nascido tenha recebido a instilação ocular do nitrato de prata a $1 \%$.

3. Orientação dos pais e familiares do recém-nascido sobre a conjuntivite química e a gonocócica.

Os pais e os familiares do recém-nascido devem ser orientados quanto aos sinais oculares anormais a serem observados no domicílio e as providências a serem tomadas, pois a permanência dos recém-nascidos normais em berçários, em geral, é de 3 dias e o periodo de incubação do gonococo é de 3 a 5 dias, podendo se estender até 14 dias, após o nascimento.

A causa da irritação química após a instilação ocular do nitrato de prata deve ser explicada aos pais do recém-nascido para diminuir a ansiedade dos mesmos.

4. Orientação e supervisão constante do pessoal que aplica o Método de Credé nos recém-nascidos.

Os responsáveis pelo Centro Obstétrico ou Berçário (médico e enfermeira) devem orientar e supervisionar constantemente o pessoal da maternidade que atende ao recém-nascido, quanto à finalidade e ao procedimento do Método de Credé, com ênfase nas dificuldades de execução da técnica de instilação ocular.

5. Maior enfoque sobre a utilização do Método de Credé, para os alunos das escolas de enfermagem e de medicina.

6. Divulgação, orientação e supervisão contínuas pelos órgãos competentes da Secretaria de Estado da Saúde, nos hospitais e nas maternidades, do seguimento das "Norma Técnica Especial que dispõe sobre a instilação obrigatória da solução de nitrato de prata a $1 \%$ nos olhos do recém-nascido" - Secretaria de Estado da Saúde do Governo do Estado de São Paulo - Decreto n. 9.713 de 19 de abril de 197769 . 
A Secretaria de Estado da Saúde do Governo do Estado de São Paulo, por intermédio das Unidades Sanitárias, está distribuindo, gratuitamente, os frascos com solução de nitrato de prata a $1 \%$ e os folhetos explicativos dessa Norma Técnica Especial, a todos os hospitais e às pessoas, profissionais ou não, que prestam assistência à parturiente, como um meio de facilitar a aplicação do Método de Credé e conseqüentemente erradicar a conjuntivite neonatal gonocócica e a cegueira devido a essa doença.

TSUNECHIRO, M. A. Bibliografy review about prophylaxis of gonococcal ophthalmia in the newborn. Rev. Esc. Enf. USP, São Paulo, 13(3):275-286, 1979.

In 1881, Credé introduced the ocular instillation of silver-nitrate solution in the newborn, after the birth, for the prophylaxis of gonococcal ophthalmia neonatorum. Although the Credé Method has been used for almost one hundred years, there is controversy among authors about the indications, the way of application and the replacement of anti-bacterial agent. The studies about gonococcal ophthalmia neonatorum and gonorrhea in pregnant women were all made in hospitals; no national statistics are available. The problems of failure and risk of Credé Method is attributed to the improper application of silver-nitrate solution. The author suggests continuation of the routine of Credé Method in all newborns.

\section{REFERENCIAS BIBLIOGRAFICAS}

1. ALLEN, J. H. \& BARRERE, L. E. Prophylaxis of gonorrheal ophthalmia of the newborn: comparison of effectiveness of penicillin and silver nitrate. J. Amer. med. Ass., Chicago, 141(8): 522-6, Oct. 1949 .

2. ALLUE, X.; RUBIO, T.; RILEY JUNIOR, H. D. Gonococcal infections in infants and children. Clin. Pediat., Philadelphia, 12(10): 584-8, Oct. 1973.

3. AINIvinZZiATO, D. Gonorrheal ophthalmia: diagnosis and treatment. N. Y. St. J. Med., New York, 74: 1470, July, 1974.

4 ARMSTRONG, J. H.; ZACARIAS, F.; REIN, M. F. Ophthalmia neonatorum: a chart review. Pediatrics, Springfield, 57(6): 884-92, June, 1976.

5. BARRETT-CONNOR, E. Gonorrhea and the pediatrician. Amer. J. Dis. Child., Chicago, 125: 233-8, Feb. 1973.

Gonorrhea. Current Problems in Pediatrics, Chicago, 3(11): 3-31, Sept, 1973

7. BARSAM, P. C. Current concepts: specific prophylaxis of gonorrheal ophthalmia neonatorum. A review. New Engl. J. Med., Boston, 274: 731-4, Mar. 1966.

8. BELFORT JUNIOR, R.; IMAMURA, P. M.; BONOMO, P. P. Avaliaçăo da profilaxia da oftalmia neonatal na cidade de Sāo aPulo. Arch. bras. Oftal., São Paulo, 38: 124-40, 1975.

9. BERENS, C. \& FOOTE, F. M. Penicillin or silver nitrate as a prophylactic against ophthalmia neonatorum? Amer. J. publ. Hlth, New York, 38(12): 1680-2, Dec. 1948.

10. BICKEL, J. E. Sodium sulfacetimide for the prophylaxis of gonorrheal ophthalmia neonatorum: preliminary report. J. Pediat., Saint Louis, 37: 854-7, 1950.

11. BLAKE, F. G.; WRIGHT, F. H.; WAECHTER, E. H. Atención de enfermaría para el recién nacido enfermo. In: - Enfermería pediatrica. 8. ed. México, Interamericana, 1971. cap. 10 , p. $164-80$.

12. BOONE, W. B.; DOUGHMAN, D. J.; HARRIS, J. E. Ophthalmia neonatorum: value of prophylactic treatment. Minn. Med., Saint Paul, 56: 940-3, Nov. 1973.

13. BOTELLA LLUSIA, J. Transtornos generales del aparato genital. In: — Tratado de ginecologia: enfermedades del aparato genital feminino. 8. ed. Barcelona, Cientifico-Médica, 1967. cap. 24, p 363-81.

14. BROWN, W. J. Trends and status of gonorrhea in the United States. J. Infect. Dis., Chicago, 123(6): 682-7, June, 1971.

15. BROWN, W. M.; COWPER, H. H.; HODGMAN, J. E. Gonococcal ophthalmia among newborn infants at Los Angeles County General Hospital, 1957-1963. Publ. Hlth Rep., Washington, 81(10): 926-8, Oct. 1966.

16. CAMPOS SALAS, A. Problemas en el control de la blenorragia. In: ORGANIZACION PANAMERICANA DE LA SALUD Enfermedades venéreas como problema de salud nacional e internacional: discusiones técnicas de la Conferencia Sanitaria Panamericana. 18.". Washington, OPS/OMS, 1971. p. 57-68 (Publicación científica, 220).

17. CAVE, V. G.; BLOOMFIELD, R. D.; HURDLE, E. S.; GORDON, E. W.; HAMMOCK JUNIOR, D. Gonorrhea in the obstetric and gynecologic clinic: incidence in a voluntary hospital in a urban community. J. Amer. med. Ass., Chicago, 210(2): 309-11, Oct. 1969.

18. CHARLES, A. G.; COHEN, S.; KASS, M. B.; RICHMAN, R. Asymptomatic gonorrhea in prenatal patients. Amer. J. Obst. Gynec., Saint Louis, 108(4): 595-9, Oct. 1970.

19. CHRISTIAN, J. R. Comparison of ocular reactions with the use of silver nitrate and erythromy. cin ointment in ophthalmia neonatorum prophylaxis. J. Pediat., Saint Louis, 57(1): 55-60, July, 1960.

20. CLARK, S. G. \& CULLER, A. M. Aureomycin as prophylaxis against ophthalmia neonatorum. Amer. J. Ophthal., Chicago, 34: 840-7, 1951.

21. CREDÉ, C. S. F. Die verhultung der augenentzlindung der neugeborenen. Arch. . Gynaekologle, Berlin, 17:50-3, 1881 . 
22. DAVIDSON, H. H.; HILL, J. H.; EASTMAN, N. J. Penicillin in the prophylaxis of ophthalmia neonatorum. J. Amer. med. Ass., Chicago, 145(14):1052-5, Apr. 1951.

23. DENNIS, R. H. Why prophylaxis for ophthalmia neonatorum? J. Maine med. Ass., Brunswick, Maine, 57:27-8, Feb. 1966.

24. DIECKMAN, W. J. The prophylaxis of gonorrheal ophthalmia neonatorum. Amer. J. Obstet. Gynec., Saint Louis, 65(5):1155-9, May, 1953.

25. FORBES, G. B. \& FORBES, G. M. Silver nitrate and the eyes of the newborn. Amer. J. DisChild., Chicago, 121(1): 1-3, Jan. 1971.

26. FRANKJIN, H. C. Prophylaxis against ophthalmia neonatorum. Clinical comparison of penicillin and silver nitrate: a preliminary report. J. Amer. med. Ass., Chicago, 134: 1230-5, Aug, 1947.

27. FRIENDLY, D. S. Gonococcal conjunctivitis of the newborn. Clin. Proc. Child. Hosp., Washington, 25(1): 1-9, Jan. 1969.

28. Gonorrhea in the obstetric clinic. J. Amer. med. Ass., Chicago, 211(1): 124, Jan. 1970.

29. GREENBERG, M. \& VANDOW, J. E. Ophthalmia neonatorum: evaluation of different methods of prophylaxis in New York City. Amer. J. publ. Hlth, New York, 51(6): 836-45, June, 1961.

30. GIFFIN JUNIOR, R. B. Eye damage in newborns from use of strong silver nitrate solutions. Calle. Med., San Francisco, 107(2): 178-81, Aug, 1967.

31. HANDSFIELD, H. H.; HODSON, W. A.; HOLMES, K. K. Neonatal gonococcal infection: orogastric contamination with Neisseria gonorrhoeae. J. Amer. med. Ass., Chicago, 225(7): 697-701, Aug. 1973.

32. HARDYMENT, A. F.; WILSON, R. A.; COCKCROFT, W.; JOHNSON, B. Incidence and bacteriology of conjunctivitis related to different methods used in prophylaxis of ophthalmia neonatorum. Pediatrics, Springfield, 25(5): 919-20, May, 1960.

33. HOLMES, K. K. Gonococcal infection: clinical, epidemiologic and laboratory perspectives. Advanc. intern. Med., Chicago, 19: 259-85, 1974.

34. INGALLS, A. J. \& SALERNO, M. C. Labor and delivery. In: health nursing. 3. ed. Saint Louis, Mosby, 1975. cap. 9, p. 80-117

35. ISRAEL, K. S.; RISSING, K. B.; BROOKS, G. F. Neonatal and childhood gonococcal infections. Clin. Obstet. Gynec., New York, 18(1): 143-51, Mar. 1975.

36. KRAUS, G. W. \& YEN, S. S. C. Gonorrhea during pregnancy. Obstet. Gynec., New York, 31(2): 258-9, Feb. 1968.

37. LEFF, M. The care of the eyes in the newborn: a report on 4.500 cases. West. J. Surg., Seatle, 59: 176-7, Apr. 1951.

38. LEHRFELD, L. Prophylaxis against ophthalmia neonatorum. J. Amer. med. Ass., Chicago, 135: 306, Oct. 1947.

39. Prevention of blindness in the newborn. J Amer. med. Ass., Chicago, 143: 1360 , Aug. 1950.

40. LERMAN, S. J. Why not use topical penicillin? Pediatrics, Springfield, 58(2): 302, Aug. 1976.

41. LeROUX, R. S. \& YEE, S. S. The physiological basis of neonatal nursing. In: CLAUSEN, J. P.; FLOOK, M. H.; FORD, B.; GREEN, M. M.; POPIEL, E. S. Maternity nursing today. New York, McGraw-Hill, 1973. cap. 28, p. 638-86.

42. MALLEK, H.; SPOHN, P.; MALLEK, J. On the comparative use of silver nitrate and penicillin in the eyes of the newborn. Canad. med. Ass. J., Toronto, 68: 117-9, Feb. 1953.

43. MANN, I. Clinical observations on the prophylaxis of ophthalmia neonatorum. Brit. J. Ophthal., London, 38(12): 734-41, Dec, 1954.

44. MARGILETH, A. M. Comparison of ocular rections using penicillin and bacitracin ointments in ophthalmia neonatorum prophylaxis J. Pediat., Saint Louis, 51: 646-51, 1957.

45. MARLOW, D. R. Care of newborn. In: - Textbook of pediatric nursing. 4. ed. Philadelphia, Saunders, 1973. cap. 7, p. 127.56.

46. Conditions of the newborn requering imediate or short term care. In: - - Text book of pediatric nursing. 4. ed. Philadelphia, Saunders, 1973. cap. 10, p. 193-222.

47. MATHESIUS, V. J. Die wahrheit über die Credésche prophylaxe der neugeborenenblennorrhoe. Gynaecologia, Basel, 164: 274-8, 1967.

48. MATHIEU JUNIOR, P. L. Comparison study: silver nitrate and oxytetracycline in newborn eyes. A comparison of the incidence of conjunctivitis following the instillation of silver nitrate or oxytetracycline into the eyes of newborn infants. J. Dis. Child., Chicago, 95(6): 609-11, June, 1958.

49. MELLIN, G. W. \& KENT, M. P. Ophthalmia neonatorum: is prophylaxis necessary? Pediatrics, Springfield, 22(5): 1006-15, Nov. 1958.

50. MELLIN, G. W. Ophthalmia neonatorum: yesterday, today and tomorrow. Slght-sav. Rev., New York, 31(2): 102-13, Summer, 1961 .

51. NATIONAL SOCIETY FOR THE PREVENTION OF BLINDNESS - COMMITTEE ON OPHTHALMIA NEONATORUM Control of ophthalmia neonatorum. Sight-sav Rev., New York, 43(1): 11-3, Spring, 1973.

52. NICKERSON, C. W. Gonorrhea amnionitis. Obstet. Gynec., New York, 42(6): 815-7, Dec. 1973.

53. NISHIDA, H. \& RISEMBERG, H. M. Silver nitrate ophthalmic solution and chemical conjunctivitis. Pediatrics, Springfield, 56(3): 368-73, Sept. 1975.

54. NOLAN, G. H. \& OSBORNE, N. Gonococcal infections in the female. Obstet. Gynec., New York, 42(1): 156-64, July, 1973.

55. O'BRIEN, D. Terramycin in the prophylaxis of ophthalmia neonatorum. Lancet, London, 1: 347-8, Feb. 1952.

56. ONYANGO-OGONY, P. J. \& HETLAND-ERIKSEN, J. Purulent ophthalmia neonatorum at Mulago Hospital. E. Afr. med. J., Nairobi, 52(11): 640-3, Nov. 1975

57. ORGANIZACION PANAMERICANA DE LA SALUD - Enfermedades venéreas: informe de un seminario viajero internacional en los Estados Unidos de América. Washington, OPS/OMS, 1974. (Publicación cientifíca, 280 )

58. ORMSBY, H. L. Ophthalmia neonatorum. Canad. med. Ass. J., Toronto, 72: 576-80, Apr. 1955.

59. OSTERLUND, K.; PUROLA, E.; JAHKOLA, M. The occurrence of gonorrheal ophthalmia neonatorum and the efficiency of prophylaxis. Ann. Paediat. Fenn., Helsinki, 14: 23-5, 1968.

60. OTITI, J. M. L. Ophthalmia neonatorum in Mbale Hospital - Uganda. E. Afr. med. J., Nairobi, 52(11): 644.7, Nov. 1975 
61. PARISER, H. Gonorréia assintomática. Clinica Médica da América do Norte, Rio de Janeiro, 56: $1127-32$, set. 1972 .

62. PEARSON, H. E. Failure of silver nitrate prophylaxis for gonococcal ophthalmia neonatorum. Amer. J. Obstet. Gynec., Saint Louis, 73(4): 805-7, Apr. 1957.

63. PIEROG, S.; NIGAM, S.; MARASIGAN, D. C.; DUBE, S. K. Gonococcal ophthalmia neonatorum: relationship of maternal factors and delivery room practices to effective control measures. Amer. J. Obstet. Gynec., Saint Louis, 122(5): 589-92, July, 1975.

64. POSNER, A. C.; ANDERSON, G. D.; PRIGOT, A. Observations on the prophylaxis of ophthalmia neonatorum in a municipal hospital. Antibiotics Annual 1958-1959, New York, p. 134-7.

65. PREVENTION of blindness from ophthalmia neonatorum. New York, National Society for the Prevention of Blindness, 1939. (Publication 301).

66. PROPHYLAXIS of gonococcal ophthalmia. The Medical Letter on Drugs and Therapeutles, New York, 12: 38-9, May, 1970.

67. REEDER, S.; MASTROIANNI JUNIOR, L.; MARTIN, L. L.; FITZPATRICK, E. Conduct of human labor. In: - Maternity nursing. 13. ed. Philadelphia, J. B. Lippincott, 1976. cap. 18, p. $299 \cdot 50$.

68. RIS, H. W. Gonococcal ophthalmia neonatorum and routine screening of pregnant women for gonorrheal infection. Pediatrics, Springfield, 52(2): 303-3, Aug. 1973.

69. SxO PAULO. Estado. Decreto n. 9713 , de 19 de abril de 1977. Diário Oficlal do Estado de São Paulo, Sảo Paulo, 20 de abril de 1977. p. 4, c. 2. Aprova norma técníca especial relativa à preservaçáo da saude, dispondo sobre a instilação obrigatória da solução da prata a $1 \%$ nos olhos dos recém-nascidos (Método de Credé).

70. SARREL, P. M. \& PRUETT, K. A. Symptomatic gonorrhea during pregnancy. Obstet. Gynec., New York, 32(5): 670-3, Nov. 1968.

71. SCANLON, J. W. Screening for gonorrhea during pregnancy. Pediatrics, Springfield, 53: 288, Feb. 1974.

72. SCHMALE, J. D.; MARTIN JUNIOR, J. E.; DOMESCIK, G. Observations on the culture diagnosis of gonorrhea in women. J. Amer. med. Ass., Chicago, 210(2): 312-4, Oct. 1969.

73. SCHOFIELD, C. B. S. Medicosocial background to gonococcal ophthalmia neonatorum. Lancet, London, 2: 1182-5, Nov. 1969.

74. SCHOFIEID, C. B. S. \& SHANKS, R. A. Gonococcal ophthalmia neonatorum despite treatment with antibacterial eye-drops. Brit. med. J., London, 257-9, Jan. 1971.

75. SCHROETER, A. L. \& LUCAS, J. B. Gonorrhea: diagnosis and treatment. Obstet. Gynec., New York, 39(2): 274-85, Feb. 1972 .

76. SCHROETER, A. L. \& PAZIN, G. L. Gonorrhea. Ann. Intern. Med., Philadelphia, 72(4): 553-9, Apr. 1970.

77. SEEDORF, H. H. Is prophylactic treatment of the eyes of newborn infants still necessary? Dan. med. Bull., Copenhagen, 7(5): 128-32, Oct. 1960.

78. SHAW, E. B. Gonorrheal ophthalmia neonatorum. Pediatrics, Springfield, 52(2): 281-2, Aug. 1973.

79. - Ophthalmia in the newborn. West. J. Med., San Francisco, 122(1): 74, Jan. 1975. 80. May, 1977. Questions need for prophylaxis with silver nitrate. Pedlatrics, Springfield, 59(5): 792,

81. SMITH, C. A. \& HALSE, L. Ophthalmia neonatorum. Publ. Hlth. Rep., Washington, 70(5): 462-70, May, 1955.

82. SMITH, J. A. Ophthalmia neonatorum in Glasgow. Scot. med. J. Glasgow, 14(8): 272-6, Aug. 1969.

83. SNOWE, R. J. \& WILFERT, C. M. Epidemic reappearence of gonococcal ophthalmia neonatorum. Pediatrics, Springtield, 51(1): 110-4, Jan. 1973.

84. SOLOMONS, E.; KRAMER, B.; STEIN, W. W.; KHOL, S. G. The incidence of ophthalmia neonatorum without prophylaxis. Amer. J. Obstet Gynec., Saint Louis, 78(3): 513-8, Sept. 1959.

85. THATCHER, R. W. \& PETTIT, T. H. Gonorrheal conjunctivitis. J. Amer. med. Ass., Chicago, 215(9): 1494.6, Mar. 1971.

86. THOMPSON, T. R.; SWANSON, R. E.; WIESNER, P. J. Gonococcal ophthalmia neonatorum: relationship of time of infection to relevant control measures. J. Amer. med. Ass., Chicago, 228(2): 186-8, Apr. 1974.

87. THYGESON, P. Historical review of oculogenital disease. Amer. J. Ophthal., Chicago, 71(5): 975-85, May, 1971.

88. WATERS, J. R. \& ROULSTON, T. M. Gonococcal infections in a prenatal clinic. Amer. J. Obstet. Gynec., Saint Louis, 103(4): 532-6, Feb. 1969.

89. WATTS, S. G. \& GLEICH, M. M. Penicillin silver nitrate prophylaxis against gonorrheal ophthalmia of the newborn: preliminary report on use of penicillin and silver nitrate combined and of silver nitrate alone. J. Amer. med. Ass., Chicago, 143(7): 635-7, June, 1950.

90. WILENSKY, J. Conjunctivitis of the newborn. J. La med. Soc. State M. Soc., New Orleans, 124(12): 435-9, Dec. 1972.

91. WILlCOX, R. R. Doenças venéreas: uma visão mundial. Clínica Médica da América do Norte, Rio de Janeiro, 56: 1057-71, set. 1972. 